\title{
Successful Surgical Control of Peritoneal Dissemination of Hepatocellular Carcinoma
}

\author{
Norio Yokoigawa Tokuhiro Ogura A.-H. Kwon \\ Department of Surgery, Kansai Medical University, Moriguchi, Japan
}

\section{Key Words}

Hepatocellular carcinoma - Peritoneal dissemination · Surgical control

\begin{abstract}
Treatment for the peritoneal dissemination of hepatocellular carcinoma (HCC) has not yet been established. We report a patient with HCC associated with disseminated intra-abdominal tumor. A 74-year-old man was admitted to our hospital. Computed tomography showed a $3 \times 3 \mathrm{~cm}$ mass in the left hepatic lobe and a giant mass between the stomach and spleen. At laparotomy, the tumor was seen in the medial segment and evaginated to the diaphragm. There was a tumor between the stomach and spleen, confirmed as a $5 \times 5 \mathrm{~cm}$ tumor evaginated from the left diaphragm, and a $7 \times 7 \mathrm{~cm}$ tumor adhesive to the spleen. These two tumors were not continuous and were separated. Furthermore, we confirmed a $10 \times 10 \mathrm{~cm}$ tumor in the pelvic cavity. We performed partial hepatectomy, resection of the tumor evaginated from the diaphragm, resection of the tumor of the spleen and tail of pancreas, and resection of the tumor in the pelvic cavity. Histopathologically, all resected tumors were confirmed to be well-differentiated HCC. HCC rarely disseminates intraperitoneally. It is considered that the peritoneal dissemination of HCC occurred from poorly differentiated or undifferentiated type. Then this report is a rare case. Although surgical treatment of peritoneal dissemination of HCC is not curative, surgery may improve survival and provide good quality of life in selected cases.
\end{abstract}

\section{Introduction}

Peritoneal dissemination of hepatocellular carcinoma (HCC) occurs rarely and is usually considered a terminal stage. Surgical operation is considered to be of little value. Some reports have described peritoneal dissemination of HCC after needle biopsy or rupture. Dissemination of HCC was shown along the needle biopsy tract to the abdominal wall and by rupture of HCC and as the consequence of cancer peritonitis by tumor recurrence. It should be considered that needle biopsy of the liver tumor can 
lead to dissemination to the abdominal wall. Rupture of HCC is fatal and needs emergent treatment, as tumor cells seed into the peritoneal cavity. Cancer peritonitis was shown in most cases with dissemination of HCC. However, dissemination of HCC without cancer peritonitis to the peritoneum apart from a primary tumor has not been reported. In our case, the primary tumor was not ruptured and we had not performed needle biopsy of the liver tumor. Under these circumstances, we diagnosed the liver tumor as HCC based on elevation of tumor markers such as alpha-fetoprotein (AFP) and protein induced by vitamin $\mathrm{K}$ absence or antagonist-II (PIVKA-II). We report a case of peritoneal dissemination of HCC in which operation improved the patient's quality of life. Peritoneal dissemination is a rare presentation of HCC, and we should thus examine the characteristics of further cases.

\section{Case Report}

A 74-year-old man was admitted to our hospital because he had palpated a mass in the right lower quadrant region. Physical examination was within normal limits. The abdomen was flat, tenderness was not evident and no mass was palpable. He had no abdominal pain. Body temperature was within the normal range. He had no history of blood transfusion. Laboratory data were zinc sulfate turbidity test $19.2 \mathrm{kU}$, thymol turbidity test $10.8 \mathrm{kU}$, AFP $86.6 \mathrm{ng} / \mathrm{ml}$ and PIVKA-II $44.3 \mu \mathrm{g} / \mathrm{ml}$. HBs antigen and HCV antibody were negative. HBs antibody was present in his serum. Ultrasonography showed a $3.5 \times 2.6 \mathrm{~cm}$ high-echoic mass in the medial segment of the liver (fig. 1). Enhanced computed tomography revealed a low-density area $3 \mathrm{~cm}$ in diameter in the same lesion and a giant well-defined mass, $5 \times 10 \mathrm{~cm}$ in size, continuing from the diaphragm to left kidney between the stomach and spleen (fig. 2). Angiography showed a hypervascular tumor in the medial segment of the liver. Fluoroscopy showed a tortuous lesion from the fundus to the superior of body of the stomach. Endoscopic retrograde cholangiopancreatography did not detect abnormal findings.

Laparotomy did not reveal ascites or blood in the peritoneal cavity. In the medial segment of the liver, there was a $3 \times 3 \mathrm{~cm}$ tumor evaginated to the diaphragm. There were another $5 \times 5 \mathrm{~cm}$ tumor evaginated from left diaphragm and a $7 \times 7 \mathrm{~cm}$ tumor at the hilum of the spleen. Both tumors were not continuous and separated. There was another $10 \times 10 \mathrm{~cm}$ tumor in the pelvic cavity. This tumor was not adhesive to the surrounding tissue. We confirmed that this was a tumor of the greater omentum. Then we performed partial hepatectomy and resected the tumor of the diaphragm, the tumor of the hilum of the spleen with tail of the pancreas and spleen, and the tumor of the greater omentum. The surgical specimen are shown in fig. $3 \mathrm{a}-\mathrm{d}$. The cutting faces of the surgical specimens were similar to liver tumor. Histopathologic examination revealed a well-differentiated HCC (fig. 3e-h).

The patient's postoperative course was uneventful, and he was discharged home. Today, 2 years after the surgery, the patient remains alive without any evidence of recurrence.

\section{Discussion}

The most common sites of HCC metastasis are the lung, bone and brain. Peritoneal dissemination of HCC is rare and has been observed rarely in surgical patients. As a consequence of needle biopsy or rupture of the primary tumor, peritoneal dissemination is essentially limited to the late stage of HCC [1-4]. In our case, the primary liver tumor was not ruptured and we had not performed needle biopsy. Multiple tumor existed in the peritoneal cavity before operation. Thus, our case is very rare.

Surgical treatment has been felt to be of little value in improving survival. Despite recent advances in the diagnosis and surgical management of HCC, no effective 
treatment for late-stage peritoneal metastases has been developed. Occasionally, systemic chemotherapy was effective in cases of peritoneal dissemination of HCC. Miyake et al. [5] reported a case who developed peritoneal dissemination of HCC after hepatectomy, in whom marked tumor regression was found with a combination therapy of interferon-alpha- $2 \mathrm{~b}$ and oral tegafur/uracil.

There are some reports contributing to a patient's life prognosis by surgical treatment [6-8]. In this case, we believe that resection of peritoneal dissemination prolonged survival with a good quality of life. Peritoneal dissemination is a rare presentation of HCC, with a reported incidence of 2-16\% in autopsy or laparoscopy cases. Nakashima et al. [9] reported intraperitoneal dissemination such as diaphragm, Douglas' pouch, pancreas, spleen and gallbladder. They reported the incidence of intraperitoneal dissemination to greater omentum to be $3.8 \%$. Moreover, the rate of peritoneal dissemination of HCC was considered to be higher in cases with liver cirrhosis compared to no liver cirrhosis.

The mechanism of peritoneal dissemination from HCC was thought to be a rupture of exophytic HCC into the peritoneal cavity and subsequent seeding of metastatic deposits $[10,11]$. Sonoda et al. [12] reported that ruptured HCC evokes the risk of implanted metastasis. However, Yeh et al. [13] reported that only 4 (25\%) of 16 patients had peritoneal dissemination from preexisting ruptured HCC.

Histopathologically, peritoneal dissemination of HCC is considered to be undifferentiated or poorly differentiated type. In our case, the primary lesion was a $3 \times 3 \mathrm{~cm}$ tumor and an unruptured HCC, and all of the resected tumors were of well-differentiated type and steatosis. The metastatic tumors were larger than the primary tumor. Thus, our case showed an extremely rare condition. The real mechanism still needs to be investigated.

Yeh et al. [13] revealed that the AFP values of patients developing peritoneal dissemination from HCC after hepatectomy were high (mean 3,311.3 ng/ml). Tumor markers such as AFP played an important role in indicating the presence of peritoneal dissemination from HCC. Furthermore, Yeh and Chen [14] reported that a high AFP level and capsular invasion by the tumor cells may predispose posthepatectomy patients to peritoneal implantation from their HCCs.

In conclusion, even when disseminated HCC is found, surgical treatment should be considered for selected patients, provided that the lesions are discretely located. 


\begin{tabular}{r|l|l|l}
$\begin{array}{r}\text { Case Reports in } \\
\text { Gastroenterology }\end{array}$ & $\begin{array}{l}\text { Case Rep Gastroenterol 2012;6:612-617 } \\
\text { DOI: 10.1159/000343248 }\end{array}$ & $\begin{array}{l}\text { Published online: } \\
\text { September 26, 2012 }\end{array}$ & $\begin{array}{l}\text { @ 2012 S. Karger AG, Basel } \\
\text { ISSN 1662-0631 } \\
\text { www.karger.com/crg }\end{array}$ \\
\hline
\end{tabular}

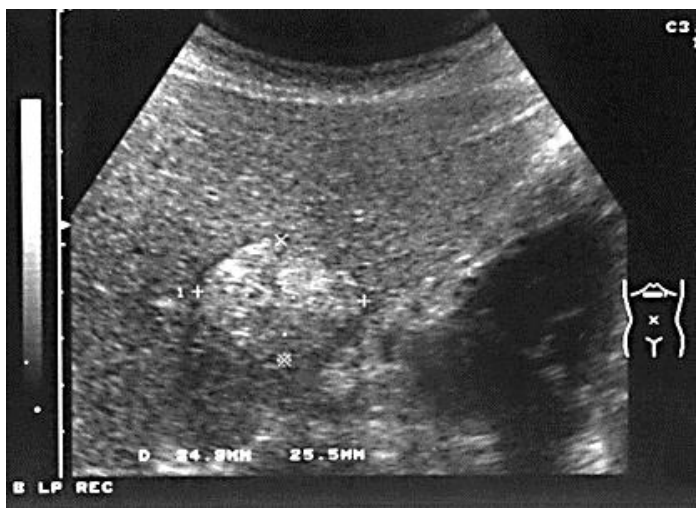

Fig. 1. Ultrasonography showed a well-defined $3.5 \times 2.6 \mathrm{~cm}$ high-echoic mass in the medial segment of the liver.
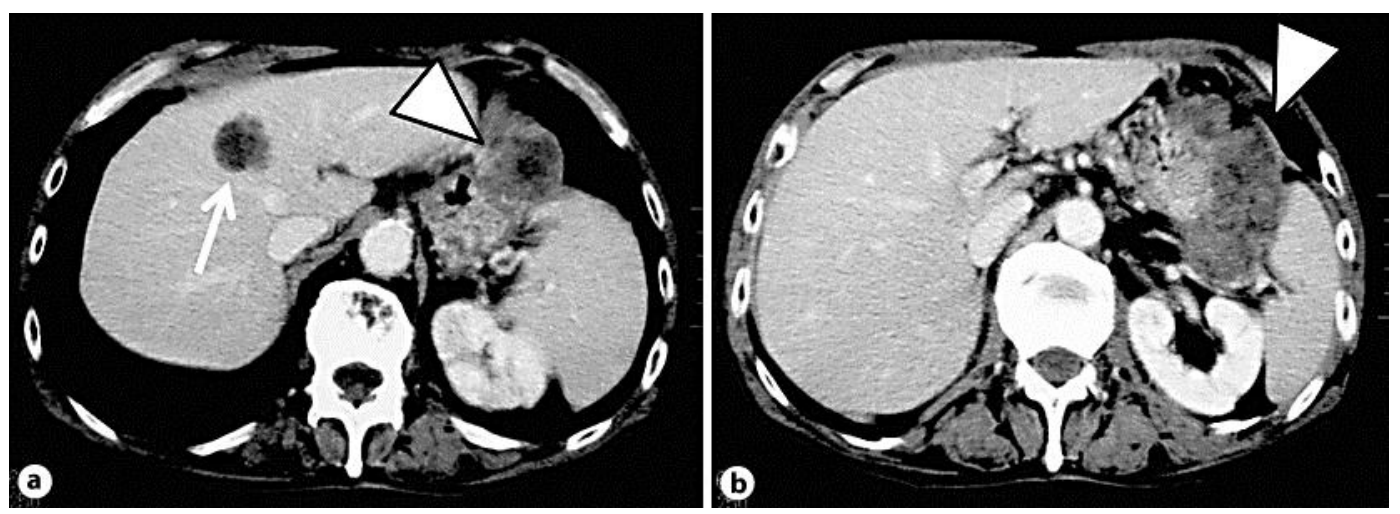

Fig. 2. Enhanced computed tomography revealed a low-density area in the medial segment of the liver (a; arrow) and a giant mass continuing from the diaphragm to the left kidney between the stomach and spleen (a, b; arrowhead). 


\begin{tabular}{r|l|l|l} 
Case Reports in & $\begin{array}{l}\text { Case Rep Gastroenterol 2012;6:612-617 } \\
\text { DOI: 10.1159/000343248 }\end{array}$ & $\begin{array}{l}\text { Published online: } \\
\text { September 26, 2012 }\end{array}$ & $\begin{array}{l}\text { @ 2012 S. Karger AG, Basel } \\
\text { ISSN 1662-0631 } \\
\text { www.karger.com/crg }\end{array}$ \\
\hline
\end{tabular}
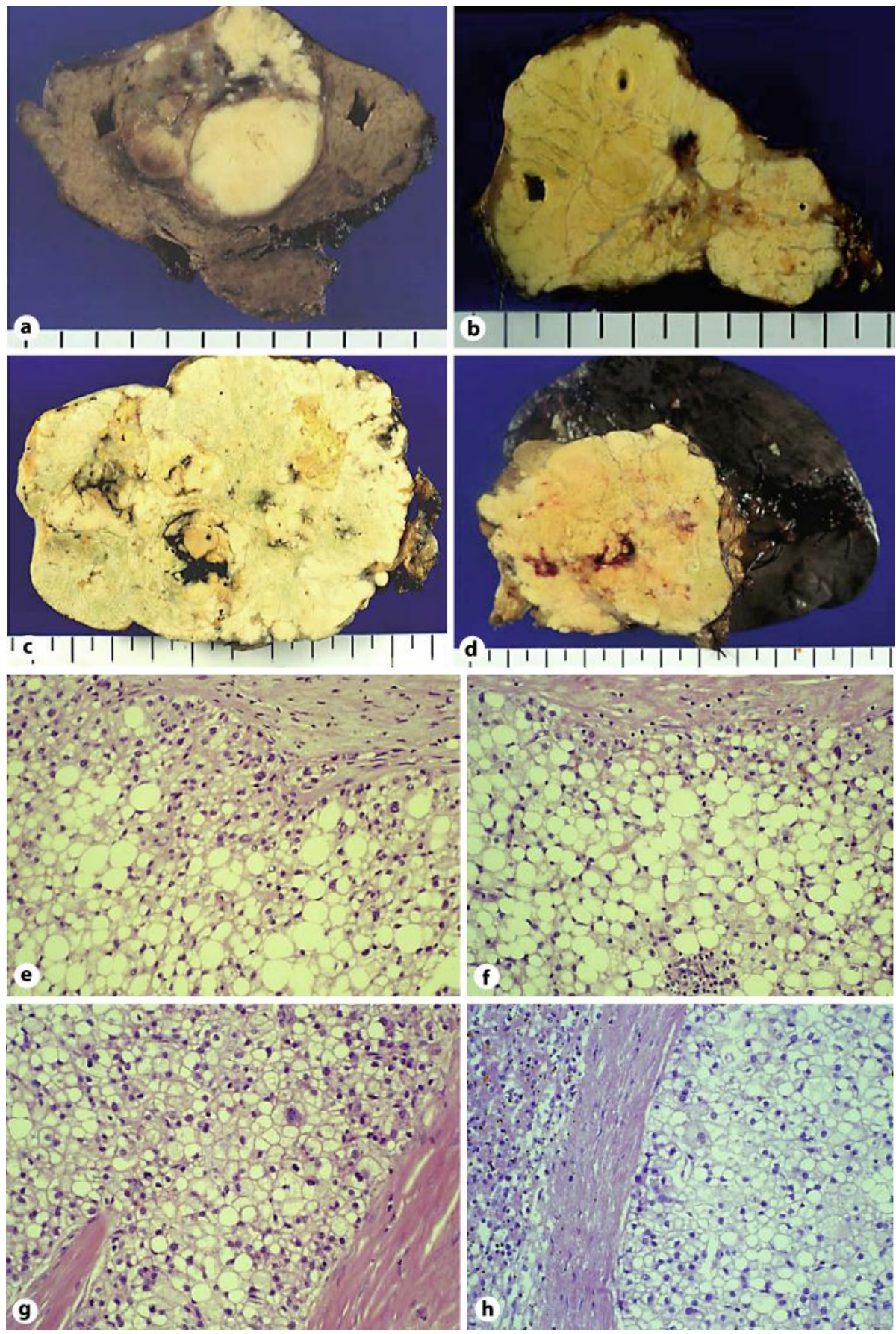

Fig. 3. a-d Surgical specimens. All specimens were solid and of well-defined shape. a Tumor of the liver. $\mathbf{b}$ Tumor of the diaphragm. $\mathbf{c}$ Tumor of the omentum. $\mathbf{d}$ Tumor of the hilum of the spleen. $\mathbf{e}-\mathbf{h}$ Histopathologic examination of all resected specimens revealed well-differentiated HCC and steatosis (hematoxylin and eosin, $\times 200$ ). e Tumor of the liver. $\mathbf{f}$ Tumor of the diaphragm. $\mathbf{g}$ Tumor of the omentum. $\mathbf{h}$ Tumor of the hilum of the spleen. 


\section{References}

$\checkmark 1$ Uenishi T, Kubo S, Hirohashi K, et al: Successful surgical control for hepatocellular carcinoma disseminated to the peritoneum: a case report. Hepatogastroenterology 2002;49:532-534.

$\checkmark 2$ Ryu JK, Lee SB, Kim KH, Yoh KT: Surgical treatment in a patient with multiple implanted intraperitoneal metastases after resection of ruptured large hepatocellular carcinoma. Hepatogastroenterology 2004;51:239-242.

-3 Takahashi H, Konishi M, Nakagohri T, et al: Aggressive multimodal treatment for peritoneal dissemination and needle tract implantation of hepatocellular carcinoma: a case report. Jpn J Clin Oncol 2004;34:551-555

4 Kaido T, Arii S, Shiota M, Imamura M: Repeated resection for extrahepatic recurrences after hepatectomy for ruptured hepatocellular carcinoma. J Hepatobiliary Pancreat Surg 2004;11:149-152.

-5 Miyake Y, Iwasaki Y, Shiraha H, Sakaguchi K, Shiratori Y: Peritoneal dissemination of hepatocellular carcinoma treated with a combination therapy of interferon-alpha-2b and oral tegafur/uracil. Intern Med 2007;46:565-569.

-6 Eriguchi N, Aoyagi S, Okuda K, et al: Successful surgical treatment for implanted intraperitoneal metastases of hepatocellular carcinoma. J Hepatobiliary Pancreat Surg 2000;7:520-523.

-7 Kosaka A, Hayakawa H, Kusagawa M, et al: Successful surgical treatment for implanted intraperitoneal metastases of ruptured small hepatocellular carcinoma: report of a case. Surg Today 1999;29:453-457.

-8 Arii S, Monden M, Niwano M, et al: Results of surgical treatment for recurrent hepatocellular carcinoma; comparison of outcome among patients with multicentric carcinogenesis, intrahepatic metastasis, and extrahepatic recurrence. J Hepatobiliary Pancreat Surg 1998;5:86-92.

9 Nakashima T, Okuda K, Kojiro M: Pathology of hepatocellular carcinoma in Japan. Cancer 1983;51: 863-877.

10 Ong GB, Chu EPH, Yu FYK, Lee TC: Spontaneous rupture of hepatocellular carcinoma. Br J Surg 1965;53: 123-129.

11 Dixon JM, Nirmul D, Eremin 0: Hemoperitoneum due to traumatic rupture of a hepatoma in a patient with hemochromatosis. J R Coll Surg Edinb 1982;27:362-363.

12 Sonoda T, Kanematsu T, Takenaka K, Sugimachi K: Ruptured hepatocellular carcinoma evokes risk of implanted metastases. J Surg Oncol 1989;41:183-186.

13 Yeh CN, Chen MF, Jeng LB: Resection of peritoneal implantation from hepatocellular carcinoma. Ann Surg Oncol 2002;9:863-868.

14 Yeh CN, Chen MF: Resection of peritoneal implantation of hepatocellular carcinoma after hepatic resection: risk factors and prognostic analysis. World J Surg 2004;28:382-386. 